\title{
The Role of Project Management Office in the Organization with the Knowledge Approach
}

\author{
Mahsa Khaksefidi \\ Member faculty of Velayat University, Iranshahr, Iran \\ *Corresponding Author. Email: m.khaksefidi@velayat.ac.ir \\ Mohammad Miri \\ Member faculty of Velayat University, Iranshahr, Iran \\ Email:m.miri@velayat.ac.ir
}

Doi:10.5901/mjss.2015.v6n6s6p11

\section{Abstract}

\begin{abstract}
Nowadays, utilization of project management is unavoidable for efficient use of resources and increased productivity. An organization unit called "Project Management Office" will be responsible for systematic development projects. Since the organizations have different dimensions and structures, project management offices are different in terms of their structural and functional characteristics. The present study investigates the project management offices as the potential knowledge agent between projects, and the project's top management. The purpose of this review is introduction of project management offices, roles, tasks, operations from the perspective of sharing knowledge And discovering whether or project management office can answer the needs of project managers in knowledge sharing or not. This article is going to present a field theory based on a better understanding of organizational project management. The following, implementation steps of the project management office in the organization and the status of this organizational unit will be discussed.
\end{abstract}

Keywords: Project Management Office, agents of knowledge, implementation of project management office

\section{Introduction}

Today, in most of the large and small project-based organizations, senior managers and project managers are faced with many challenges in allocation of resources. Therefore, in order to reduce cost and time and increase the quality in projects, there is a need for a shift from traditional to scientific management, so that it can be responsive to optimization of performance and efficiency of a project during its life. To achieve this goal, we need an organized structure for management and planning of projects. Unlike project-based organizations, a project management office has an organization-centered orientation (Tavoosi \& Teymouri, 2006). Project Management Institute defines project management office as a legal organization or entity which is responsible for different tasks related to central management and coordination of projects. Responsibilities of project management offices can involve a wide range from providing the project management with experience and support to real responsibility for the direct management of the project (PMBOK, 2008)

According to previous research, it can stated that project management office can be considered as a single organization for coordination and transfer of knowledge between organizations and projects. In the present paper, project management offices are studied as the broker of knowledge in projects. The role of knowledge broker includes developing and providing a centralized archive of information related to current projects and previous projects for better management of projects (Aubry, Hobbs, Muller \& Blomquist, 2010). Since project management offices are the center of project management strategies within an organization, establishment and use of them is of great importance. The main reasons for the use of project management offices are as follows:

- A poor and uncoordinated project management is the main factor for failure of projects. A project management office can increase the likelihood for success of projects by establishing a coordination and consistency between resources and tools.

- Using the project management office, very complicated skills are converted into software and can be easily presented and transferred. In addition, if an individual or a department presents a skill, it can be used by other individuals in whole organization as a resource. 
- Development and improvement of any organization require a centralized support. However, having such a structure in order to demonstrate and facilitate the transfer of best actions, specialties, and skills within the organization is very difficult. A project management office can provide the necessary ground for this purpose.

\section{Project Management Office}

According to the PMBOK standard, a project management office is a managerial structure which normalizes the regulatory processes of related projects and is responsible for development of methodology, determining the tools and technologies, and facilitating the sharing of resources. In fact, a project management office is a center for directing a project but it is not restricted to that project and can also involve plans and portfolios.

PMO could stand for one of the following phrases:

P3O or Portfolio, Program, and Project Office. This standard is used for establishment of project management offices. According to PMBOK 2012 standard, various structures of project management offices depending on the degree of control and influence on internal projects of an organization include supporting organization, controlling organization, and guiding organization.

Project management office is one of the best choices for integration of data and information obtained from strategic cooperation of projects and investigation of how the strategic objective are achieved at higher levels. Additionally, project management office is a natural interface between projects, programs, and portfolios of companies and measurement systems such as the Balanced Score Card. Project management office can directly affect the improvement of the following items in a project:

- Reduced probability of failure: $30 \%$

- Productivity: $22 \%$

- Project completion at the specified time: $19 \%$

- Project completion at the specified cost: $25 \%$

- Increased customer satisfaction: 22\%

- Alignment of project results with the objectives: $39 \%$

- $\quad$ The cost saved in each project: $15 \%$

Increasing the capacity of the project management office can increase the value of an organization. According to statistics in 2010, this increase in small firms have been equal to 48\% (Söderlund, 2011). Mature project management offices, receive less training at first and then, at advanced levels, are more trained on leadership and skill strategies. These offices will be more legitimate by having a higher organizational project management maturity and their high performance increases the maturity level of project management in organizations. Maturity of project management offices and maturity of organizational project management are highly interdependent, as any attempt to develop the project management office in an organization without considering the status of organizational project management will be doomed to failure. There is an important balance point between the development of performance and the value created by a project management office and different organizational situations (Artto, Davies, Kjuala \& Prencipe, 2011). According to strategies for development of project management offices in China, development of these offices occurs in two steps of gradual development and single-stage development. In gradual development, the project management office is firstly established with limited functions and then it is developed along with its improved performance and increased effectiveness. In single-stage development, with the establishment of management at the macro level, functions of the project management office are very basic. In this approach, the projects guided by the senior management of an organization are used for passing the knowledge and experiences.

\section{Project Management Office as a Knowledge Agent}

Project-based organizations mainly learn knowledge through integration of experiences among the participants in the project and project members. However, projects naturally tend to prevent knowledge sharing, because the project managers are primarily focused on time, products or services, and timely delivery and not on knowledge sharing activities (Pemsel \& Wiewiora, 2013). Time pressure and the temporary nature of projects mean that the end of a project is often the end of a collective learning activity. If the knowledge accumulated throughout a project is not effectively shared with other projects and the main organization, it would be irreparably lost and this is a serious problem in project-based organizations. Project management office can play the role of a scientific broker and record, classify, and share the information and experiences obtained from projects (Turner, Ledwith \& Kelly, 2010). The tasks of project management offices are as follows: 
- Management of measures: Establishment and application of information system, documents archive management, management of customers interfaces, management of a database of tips and risks learned and applying them, design and repair of project's scoreboard, ensuring the follow-up of the required processes, organizing and structuring the project, standardization of report forms, support for problem solving, preparation of project booklet, standard inspections of the project, and identification and documentation of the best methods.

- Infrastructure management: Secondary tasks of the way of running the project, investigation, organizing, structuring, providing the facilities and tools.

- Integration of resources: Secondary tasks of resource management, education, career advancement, and group progress.

- Technical support: Secondary tasks of consultation, planning, project audit, and recovery.

- Evaluation, analysis, and selection of projects: Coordination between projects, participation in strategic planning, management of securities, identification, selection, and prioritization of new projects, program management, investigation, project definition and planning, and analysis of the costs and benefits of projects.

- Training and consultation: Empowerment of individuals, supporting the project management within the organization, providing helpful pieces of advice to project managers, knowledge acquisition and sharing, facilitating the reuse, facilitating the communications, providing helpful pieces of advice to project with problems, and providing the required facilities and opportunities for training the project management.

- Monitoring and control: Monitoring and controlling implementation, profit management, allocation of resources to various projects, project review and inspection, audit guide, and risk management.

- Managerial supports: Providing recommendations to higher level managers, performing specialized tasks for project managers, checking the network and environment, recruitment, selection and evaluation of project managers and determining their wages, strengthening the economy in terms of scale and scope, providing support for facilities and equipment, planning, and customer relationship management, coordination of vendors or contractors relationship management, holding the meetings for beginning of projects, recording and following up the changes made in project requirements, and collection of project resources throughout the organization.

- Career orientation: Secondary tasks of project securities management, customer relationship management, of vendors or contractors relationship management, career performance management, ensuring the compliance with the required processes, sorting, summarizing, and reporting the information on project and plans progress through the extraction of simultaneous projects (economy empowerment, such as the use of specialized skills and common tools), knowledge sharing, and facilitating the reapplication (pattern, software modules, and design protocols).

\section{The Difference between Project Managers and Project Management Office}

At first, it seems that there is an overlap between the concepts of project management and project management office, but the reality is different. Studied have shown that there are some differences between these two concepts in terms of performance, objectives, and planning that some them are as follows:

1- The project managers and a project management office pursue different goals and go forward based on different needs. In any case, all these efforts are aligned with the strategic needs of the organization.

2- A project manager is responsible for realization of specific objectives under the project constraints, while a project management office is an organizational structure with specific requirements which may also involve a general view of an enterprise.

3- A project manager usually focuses on the specific objectives of project, while a project management office manages the limited changes and the content of general program and may consider them as potential opportunities for achieving the desired goals.

4- A project manager manages the resources allocate to a project in a way to better achieve the objectives of the project, while a project management office optimizes the application of organizational resources shared among the projects.

5- A project manager manages the content and scope, schedule, cost, and quality of products of working packages in a project, while a project management office manages the risks, general opportunities, and dependencies among all projects.

6- A project manager reports the project progress and other related information, while a project management 
office provides a comprehensive report and the general view of organization about the projects under supervision.

\section{Establishment of a Project Management Office}

Due to the complex nature of projects, activities of project management should be complete and efficient. Hence, organizations are always looking for better ways to manage projects in order to maximize their profit margin. For this purpose, organizations seek to optimize processes, increase productivity, and gain net profit. Since many parameters such as human resources, technology, communications, and other resources are involved in the project management, direct management of the projects by the senior manager of an organization could be risky. Therefore, project management office, as a powerful part of an organization, is an ideal strategy for building and maintaining strong project management activities. Establishment of a project management office is like any other organizational change, so it requires a strong strategy and getting use of experiences (Tavoosi \& Teymouri, 2006). Steps for establishment of a project management office are as follows:

Phase 1: Promoting the culture for establishment of a project management office in an organization in order to identify and analyze the needs, weaknesses, and basic problems in project management. One of the factors that should studied in this part is the surrounding environment of an organization which involves the resources (staff, skills, investment, project tools, etc.), organizational readiness (organizational culture, organizational support, and so on), and the model of running the affairs.

Phase 2: Setting the aspirations, missions, and scope of a project management office in line with strategic plans of an organization. By determining the missions, the size and scope of the project management office will be specified to a large extent, because the management expectations and missions can reveal the extent of influence and authorities of the project management office. Therefore, missions should be defined very carefully, because mission and aspiration are conceptually very similar to each other. The same way can be passed for determining the aspirations and mission, but you need to be ambitious and optimistic for determining the missions, while setting the aspirations requires a more scientific and realistic view.

Phase 3: Determining requirements for the establishment of a project management office, such as definition of an organizational structure, determining the number of required employees, and methodological framework of project management. In defining and determining the processes of a project management office, some items such as territory management, quality management, and so on should take into account and the educational needs and requirements should be met by determining and defining the criteria for revision of processes and performance.

Phase 4: Evaluation of the determined requirements and providing them. After determining the requirements, they should be evaluated in order to prevent problems and obstacles in the early stages of establishment of the project management office. Sometimes, this phase is integrated with Phase 3. Finally, after the establishment of the project management office, the organization will move towards the improvements listed.

Phase 5: Evaluation and continuous improvement of the project management office. Shortly after the beginning of the project management office, validity of done and undone works and activities can be assessed by desired criteria. According to the desired criteria of any organization and the weaknesses and strengths of the project management office, some recommendations, proposals, and strategies for progress and development of design and performance of this office can be presented in this phase. Development of progress and improvement strategy is possible through evaluation of the performance of this office from the past to the present.

\section{The Results of Designing and Implementation of a Project Management Office}

For the sharing of knowledge and information integration, the project management office is able to manage the education retrospectively, that is, making use of experiences of previous projects to transfer information to future projects. The purpose is to ensure proper feedback on the management and control of future projects. Some of the results of effective implementation of project management office are as follows:

1- Integration of systems, methods, procedures, and guidelines for project management in projects under the supervision of the project management office and also providing training and consultation during the implementation.

2- Preparation of lessons learned during the execution of projects and sharing them with other projects.

3- Establishment of a project management information system under a unified reporting system.

4- Integrated management of available resources (labor, machinery, and materials) 
5- Identifying the future business market and following up the necessary requirements

6- Integration of quality standards

7- Creating a position of guidance and advice for project managers (the layer between project managers and senior managers)

8- Preparation and use of a database of successful secondary contractors and consultants in projects

9- Preparation and use of a database of the prices of secondary contractors in projects

10- Central supervision of time and cost (by considering the value gained in the projects based on modern methods)

11- Following up the use of modern methods

12- Identifying the talented individuals with capabilities in project management and preparing the way for future growth

13- Preparation of a list of weaknesses, strengths, opportunities, and threats and proposing the solutions

14- Development of guidelines for annual schedule based on the budget and making efforts for implementing them

15- Assessment of the existing and newly-issued guidelines by the deputies

16- Establishment of managers circulation system

\section{Is the Project Management Office an Overhead Cost?}

Some traditional organizations view the project management offices as an overhead cost. This is due to the small size of their organization and lack of need for the project management office. In such organizations, the senior manager can personally take the responsibility of project management operations. However, this office is not regarded as an overhead cost in organization which carry out large projects. Currently, the world's economy is undergoing a period of recession, so many companies cut their expenses in order to survive. Among the ways to do so, layoff and elimination of some part are the favorite option of managers. The project management office is an easy victim in such cases, because its impact on net profit of the company is not evident. Hence, the main challenge for the project management offices is justifying their performance for the senior managers of an organization or firm.

\section{Why Project Management Offices Fail?}

Many organizations establish a project management office without having a clear and correct understanding of the roles, requirements, outlook, and path of such offices. They simply adopt the traditional patterns of project management offices without considering the organizational needs. From a scientific point of view, a project management office can be a single organization for coordinating and facilitating the communication between knowledge and other resources, project-based organizations and projects, and organization and knowledge. According to statistics, only one-third of project management offices are effective and rest of them are not working as expected. This is one of the main concerns and doubts of senior managers about the establishment of a project management office in their organizations. One of the main reasons for the failure of project management offices is the lack of support by the senior management. In most cases, the senior management does not have enough knowledge on how to support guide a project management office. However, the inabilities of these offices can also be the reason for their failure which is mainly due to weakness in human resources and the resources allocated to these offices.

\section{Conclusion}

Project management knowledge, from all its aspects, is an essential and crucial need for our country. With a glance at the number and size of investment in current projects and the projects that should be implemented in the current decade in infrastructural sectors as planned, we can perceive the top priority and importance of this strategic issue in Iran. However, the knowledge and skills of scientific management of projects are not addressed in our country as it is expected to be in line with this strategic objective. Failure, numerous delays, and large number of unfinished infrastructural projects are the main consequences of non-institutionalization of principles of scientific management of projects.

Nowadays, implementation, management, and operation of projects are not possible without learning and applying the techniques of project management and the current status shows that reliance on traditional management practices does not suffices for optimum implementation of projects. Prolonged duration of projects, evident quality weakness of the implemented projects, the higher costs of projects than the initial estimation, and so on can be mentioned as part of the problems chain in projects implemented in our country. In this regard and in order to overcome these problems, 
establishment of project management offices can be very helpful in the development of scientific and practical studies.

\section{References}

Tavoosi. A, Teymouri. A; 2006; Project Management Offices; Journal of Tadbir, Vol. 18, No. 170.

Project Management Office; PMBOK: 2008.

Aubry, M., Hobbs, B., Muller, R., Blomquist, T., (2010). Identifying forces driving PMO changes. In: PMI (Ed.), PMI Research and Education Conference 2010-Defining the Future of Project Management. PMI, Washington, D.C

Söderlund, J., (2011). Theoretical foundations of project management. In: Morris, P.W.G., Pinto, J.K., Söderlund, J. (Eds.), The Oxford Handbook of Project Management. Oxford university press, New York, pp. 37-64.

Artto, K., Davies, A., Kjuala, J., Prencipe, A., (2011). The project business analytical framework and research opportunities. In: Morris, P.W.G., Pinto, J.K., Söderlund, J. (Eds.), The Oxford Handbook of Project Management. Oxford University press, New York, pp. 133-153.

S. Pemsel, A. Wiewiora, (2013), Project management office a knowledge broker in project-based organisations, / International Journal of Project Management (31) 31-42.

Turner, R., Ledwith, A., Kelly, J., (2010), Project management in small to medium-sized enterprises: matching processes to the nature of the firm, International Journal of Project Management 28 (8), 744-755. 